\title{
Bentuk dan Makna Ritual Ma'nene' To Sarani di Toraja Utara
}

\author{
Haryeni Tamin 1 \\ Hasan $^{2}$ \\ Kasmawati ${ }^{3}$ \\ Indarwati ${ }^{4}$
}

\author{
1,2Universitas Hasanuddin \\ ${ }^{3}$ Universitas Muslim Maros \\ ${ }^{4}$ Politeknik LP3I Makassar \\ 1haryeni@unhas.ac.id ${ }^{2}$ \\ hasanali.unhas23@gmail.com, \\ 33asma89@umma.ac.id \\ 4indarwatipolinas.gmail.com
}

\begin{abstract}
Abstrak
Penelitian ini bertujuan mengetahui dan menganalisis bentuk prosesi dan makna dari ritual ma'nene' to Sarani di Kabupaten Toraja Utara. Penelitian ini menggunakan pendekatan kualitatif. Data dikumpulkan dengan metode observasi dengan menggunakan teknik catat dan wawancara (interview). Lokasi penelitian bertempat di kecamatan Denpina, kabupaten Toraja Utara, Sulawesi Selatan. Hasil penelitian menunjukkan beberapa ritual ma'nene' to sarani yang dilakukan oleh masyarakat kecamatan Denpina, yaitu ma'bukka' liang(membuka liang kuburan), ma'bawa pangan(membawa jenis makanan), masseroi(membersihkan), mangallo batang rabuk(menjemur jasad), ma'palobo(mengganti pembungkus),' mangrapa(memasukkan kembali)', dan ma'tutu' liang (menutup liang kubur). Setiap prosesi yang dilakukan ini mengandung makna dan tujuan tertentu.
\end{abstract}

Kata kunci: Ritual, ma'nene, Toraja Utara

\section{Abstract}

This study aims to determine and analyze the form of the procession and the meaning of the ma'nene' to Sarani ritual in North Toraja Regency. This study uses a qualitative approach. Data were collected by observation method using notetaking and interview techniques (interview). The research location is in Denpina sub-district, North Toraja district, South Sulawesi. The results showed several ma'nene' to Sarani rituals carried out by the people of Denpina sub-district, namely ma'bukka' liang (opening graves), ma'bawa food (bringing types of food), masseroi (cleaning), mangallo Batang rabuk (drying the body), ma'palobo (replacing the 
wrapping),' mangrapa (reinserting)', and ma'tutu' liang (closing the grave). Each procession carried out contains a specific meaning and purpose.

Keywords: Ritual, ma'nene, North Toraja

\section{Pendahuluan}

Sistem tanda, seperti cara pemahaman, perhubungan, dan penciptaan merupakan definisi dari kebudayaan. Oleh karena itu, kebudayaan adalah suatu sistem yang berupa gagasan, kelakuan, dan hasil kelakuan. Selain itu, "Kebudayaan adalah hasil cipta, rasa, dan karsa manusia. Bentuk-bentuk simbolis yang berupa kata, benda, laku, mite, sastra, lukisan, nyanyian, musik, kepercayaan yang berkaitan erat dengan konsep-konsep dari sistem pengetahuannya, juga tidak dapat terpisahkan dari sistem sosial, organisasi kemasyarakatan, dan seluruh perilaku sosial". (Indarwati et al., 2018)

Salah satu suku di Sulawesi Selatan yang memiliki banyak warisan budaya, yaitu suku Toraja. Suku tersebut memiliki keunikan tersendiri sehingga perlu untuk diteliti, khususnya tradisi yang berada di Kabupaten Toraja Utara. Tradisi yang biasanya dilakukan dinamai Ma'Nene. Ritual Ma'Nene berbeda dengan Upacara Rambu Solo yang sangat terkenal dan membutuhkan biaya yang sangat besar karena harus diselenggarakan secara meriah. Ma'Nene merupakan sebuah ritual yang membersihkan jasad para leluhur yang sudah ratusan tahun meninggal dunia dan hal tersebut masih dilakukan di Desa Buntu Tariga setiap tiga tahun sekali walaupun pelaksanaanya di beberapa desa juga sudah tidak banyak yang melakukan ritual tersebut.

Kepercayaan yang dimiliki masyarakat di Kabupaten Toraja Utara sudah ada sejak ribuan tahun silam dan ritual tersebut sudah mendunia. Tradisi Ma'Nene diadakan oleh masyarakat setiap usai panen padi di Kecamatan Denpina dan sekitarnya. Ritual dilakukan sekitar bulan Juli dan Agustus dalam tiap tahunnya.

Tujuan penelitian ini adalah untuk menjelaskan ritual dan makna Ma'nene di kecamatan Denpina, kabupaten Toraja Utara. Dengan adanya penelitian ini diharapkan dapat memberi penjelasan tentang bagaimana proses ritual Ma'nene dilaksanakan dan makna setiap ritualnya.

\section{Kajian Teori}

\section{Semiotika}

Menurut De Saussure dalam (Indarwati et al., 2018) mengajukan konsep signe(tanda) untuk menunjukkan hubungan antarsignifie. "Signifie adalah makna atau konsep dari signifiant yang berwujud bunyi-bunyi bahasa. Tanda ini terdiri dari unsur makna atau yang diartikan "buku" dan unsur bunyi atau yang mengartikan dalam wujud fonem $(b, u, k, u)$, kemudian tanda "buku" ini yang lain dalam hal ini terdiri atas unsur makna dan unsur bunyinya mengacu kepada suatu referen yang berada di luar bahasa, yaitu sebuah buku sebagai sebuah alat tempat menulis". Dengan demikian, jika kata 'buku' suatu hal yang menandai (tanda linguistik) maka sebuah buku yang merupakan alat tempat menulis adalah hal yang ditandai.

Kata dan makna tersebut tersebut bersifat arbitrer, yang artinya hubungan antara penanda dan petanda tidak memiliki hubungan yang wajib, tetapi memiliki hubungan yang bersifat konvensional atau kesepakatan suatu masyarakat mengenai bahasa yang digunakan karena jika suatu masyarakat tidak memiliki sebuah konvensi dalam berbahasa maka komunikasi yang digunakan akan mengalami hambatan. Dengan 
demikian, secara sinkronis hubungan antara kata dan makna dalam suatu bahasa tidak berubah, sedangkan secara diakronis kemungkian aka nada perubahan seiring perkembangan suatu budaya dalam masyarakat.

Greetz, dalam kajian semiotika mengatakan bahwa cara untuk menafsirkan suatu kebudayaan adalah dengan memaparkan konfigurasi atau simbol-simbol bermakna secara mendalam dan menyeluruh. Oleh karena itu, simbol-simbol yang ada dalam kehidupan masyarakat yang sesungguhnya akan menunjukkan cara para masyarakat tersebut untuk melihat, merasa, dan berpikir tentang dunia mereka dan bertindak berdasarkan nilai-nilai yang sesuai. Jadi, Greetz (dalam Indarwati et al., 2020) mengatakan bahwa "Kebudayaan adalah semiotik; hal-hal yang berhubungan dengan simbol-yang tersedia di depan umum dan dikenal oleh masyarakat yang bersangkutan".

\section{Makna dan Simbol}

Makna dari makna merupakan gabungan semiotik dari sisi teoritis maupun terminologi. Dalam pengertian yang luas, makna terdiri atas dua dimensi, yaitu dimensi arti (isi) dan acuan (objek). Bahkan, Ogden dan Richard dalam (Indarwati et al., 2018) membedakan "Makna tidak kurang dari dua puluh tiga makna, membedakan maknamakna itu, dan makna lain dari makna memerlukan penjelasan terminologis". Pedoman yang diambil dalam menentukan suatu istilah-istilah yang merupakan marka orientasi adalah tiga istilah, yakni makna, arti, dan acuan.

Menurut Djajasudarma dalam (Indarwati et al., 2018), "Makna dibedakan dari arti dalam semantik. Makna adalah hubungan yang ada di antara unsur-unsur bahasa itu sendiri, sedangkan arti menyangkut makna leksikal yang terdapat dalam kamus sebagai leksikon". Dalam kehidupan sehari-hari kita tidak lepas dari sebuah symbol. Simbol dapat muncul dari berbagai konteks dan digunakan untuk berbagai tujuan, misalnya cara berpakaian. Orang yang berpakaian seragam dinas menandakan dia seorang PNS.

Kebudayaan merupakan suatu sistem keteraturan dari makna dan simbol-simbol. Oleh karena itu, makna dan simbol-simbol tersebut membuat setiap individu dapat mendefinisikan dunia mereka, mengekspresikan persamaan mereka dan perasaanperasaan dalam membuat penilaian. "Semua makna budaya diciptakan dengan menggunakan simbol-simbol, (Spredley dalam Sobur, 2006:121).

Pengetahuan kebudayaan lebih dari suatu kumpulan simbol, istilah-istilah rakyat dan jenis-jenis simbol lain. Simbol atau lambang dikatakan sebuah tanda jika hubungannya untuk menggantikan sesuatu yang lainnya yang berdasarkan suatu kesepakatan masyarakat. Kebudayaan juga merupakan sistem yang berupa gagasan, kelakuan, dan hasil kelakuan. Dengan kata lain, kebudayaan adalah hasil cipta, rasa, dan karsa manusia. Kebudayaan suatu etnik merupakan instrumen atau alat dalam kehidupan masyarakatnya dengan nilai-nilai yang terkandung dalam kebudayaannya menjadi patokan sekaligus menjadi tujuan hidupnya. Pada sisi yang sama, masyarakat sebagai pelaku kebudayaan kurang menumbuhkan rasa tanggung jawab diri sebagai pewaris tradisi (Mattulada, 1985).

Menurut Kleden dalam (Indarwati et al., 2020), bahwa "Nilai sama dengan makna. Nilai atau makna dimaksud berhubungan dengan kebudayaan atau secara lebih khusus berhubungan dengan dunia simbolik dalam kebudayaan. Menurut pandangan ini, nilai terkait dengan pengetahuan, kepercayaan, simbol dan makna". Sistem nilai budaya berkaitan dengan sebuah konsep yang hidup dan tumbuh dalam alam pikiran suatu masyarakat yang sangat berkaitan dengan prinsip-prinsip yang mereka anggap sangat bernilai dalam hidup. Dalam ilmu semantik makna dibedakan dari arti sehingga makna 
merupakan pertautan yang ada di antara unsur-unsur bahasa itu sendiri (terutama katakata).

Nilai mempunyai elemen konsepsi yang mendalam pada diri manusia, yakni, emosi, perasaan, dan keyakinan-keyakinan dan hal tersebut memiliki keterkaitan dengan nilai budaya sehingga nilai yang ada dalam suatu masyarakat mampu atau lebih diutamakan dari nilai-nilai lainnya dan dijadikan kerangka acuan dalam berperilaku. De Saussure (dalam Hoed, 2008) juga mengajukan konsep signé (tanda) untuk menunjukkan hubungan antara signifié (yang ditandai) dan significant (yang menandai). Signifié adalah makna atau konsep dari signifiant yang berwujud bunyi-bunyi bahasa. Signifié dan signifiant sebagai signé linguistique adalah satu kesatuan yang merujuk pada satu referen yaitu sesuatu, berupa benda atau hal yang diluar bahasa.

Nilai budaya selain memiliki konsepsi yang bermacam-macam, terdapat juga tingkat nilai aturan-aturan khusus atau umum sehingga dengan sendirinya menyusun suatu sistem nilai budaya yang kompleks. "Simbol dapat muncul dari berbagai konteks dan dapat digunakan untuk berbagai tujuan. Ada banyak simbol yang kita saksikan dalam kehidupan sehari-haro, mulai dari hal-hal kecil, seperti cara berpakaian, status sosial berpakaian yang mewah dan glamour melambangkan kekayaan orang tersebut" (Indarwati et al., 2020).

\section{Metode}

Metode yang digunakan dalam penelitian ini, yaitu pendekatan penelitian kualitatif. Semua masalah dianalisis secara mendalam sehingga didapatkan berupa penjelasan atau gambaran mengenai hal-hal yang berhubungan dengan yang diteliti. Metode deskriptif digunakan untuk mendapatkan data secara alamiah dan pengumpulan data dilakukan dengan cara mencatat, mengklasifikasikan data, menganalisis data, dan menyimpulkan data.

Adapun, sumber data dalam penelitian ini berupa data primer dan sekunder. Data primer berupa makna dan simbol pada "ritual ma'nene to Sarana", seperti kata, frasa, dan kalimat. Data sekunder diperoleh dari berbagai sumber, seperti artikel dan wawancara dengan beberapa tokoh agama dan masyarakat yang berpengalaman dalam ritual tersebut

Dalam pengumpulan data, digunakan beberapa teknik, seperti pencatatan dan perekaman. Analisis yang digunakan, yaitu deskriptif kualitatif karena teknik tersebut menyajikan, mengintrepretasikan makna dan maksud dari data-data yang dikumpul dengan perhatian kepada catatan data tersebut.

Tujuan deskriptif adalah untuk membuat deskripsi atau gambaran secara sistematis, afaktual dan akurat mengenai fakta-fakta yang diselidiki dalam masyarakat dalam sebuah bentuk tulisan. Setelah semua data yang dibutuhkan terkumpul, langkah selanjutnya adalah menganalisis data dengan menyusun, memilah dan memilih data yang sesuai dengan tujuan penelitian. Adapun langkah yang terakhir adalah mendeskripsikan data yang diperoleh berupa tulisan yang bersifat ilmiah secara teratur dan sistematis.

\section{Hasil}

\section{Ma'bukka Liang}

Ma'bukka' liang adalah rangkaian ritual ma, nene' to sarani yang dilaksanakan pada hari pertama. Ma'bukka' liang berarti membuka liang kuburan mayat. Ma'bukka' liang menandakan bahwa ritual ma'nene' sudah dimulai. Ma'bukka' liang dilakukan oleh 
keluarga besar dari mayat yang berada dalam setiap kuburan tersebut. Sebelum prosesi ma'bukka' liang dilakukan, maka akan diawali dengan doa yang dipimpin oleh seorang dari keluarga besar. Pada saat prosesi ini berlangsung, belum terlalu banyak keluarga besar yang berkunjung. Pada prosesi ma'bukka' liang ini juga, diiringi dengan membersihkan sekitar kuburan yang dilakukan oleh para keluarga besar.

\section{Ma'bawa pangan}

Ma'bawa pangan adalah rangkaiang ritual ma'nene' to sarani yang dilaksanakan pada hari kedua. Ma'bawa pangan berarti membawa berbagai jenis makanan ataupun minuman ke kuburan, seperti kue, air mineral, gula-gula, uang, bahkan rokok. Berbagai jenis makanan dan minuman yang dibawa ini bukan untuk dimakan oleh para keluarga yang berkunjung, melainkan dibawa untuk diberikan kepada keluarga yang telah meninggal. Makna dari berbagai makanan dan minuman yang dibawa ini adalah sebagai tanda kasih sayang kita kepada keluarga yang telah meninggal. Salah satu masyarakat mengatakan bahwa" bukan berarti mereka telah meninggal jadi kita tidak dapat berbagi kepada mereka". Ini menandakan bahwa dengan membawa berbagai macam barang ke tempat kuburan keluarga, itu menandakan bahwa kita masih mengingat kepada keluarga yang telah meninggal dan masih ingin berbagi kepada mereka. Pada prosesi yang digelar di hari kedua ini, diiringi juga dengan penanaman bunga disekitar kuburan. Penanaman bunga ini bertujuan untuk memperindah halaman di sekitar kuburan. Masyarakat setempat meyakini bahwa kuburan itu merupakan rumah bagi mereka yang telah meninggal, jadi hendaknya diperlakukan seperti rumah selayaknya.

\section{Masseroi}

Ritual Masseroiyang berarti membersihkan. Dalam ritual ma'nene' to Sarani, kegiatan biasanya dilakukan dari hari pertama sampai kedua yang dilakukan oleh semua keluarga besar. Masseroi ini dilakukan karena masyarakat setempat meyakini bahwa kenyamanan para keluarga yang telah meninggal tergantung dari bersih tidaknya tempat mereka. Semua lokasi kuburan dibersihkan dengan berbagai peralatan. Semua keluarga besar dikuburan kekuarga mereka masing-masing membersihkan disekitaran kuburan.

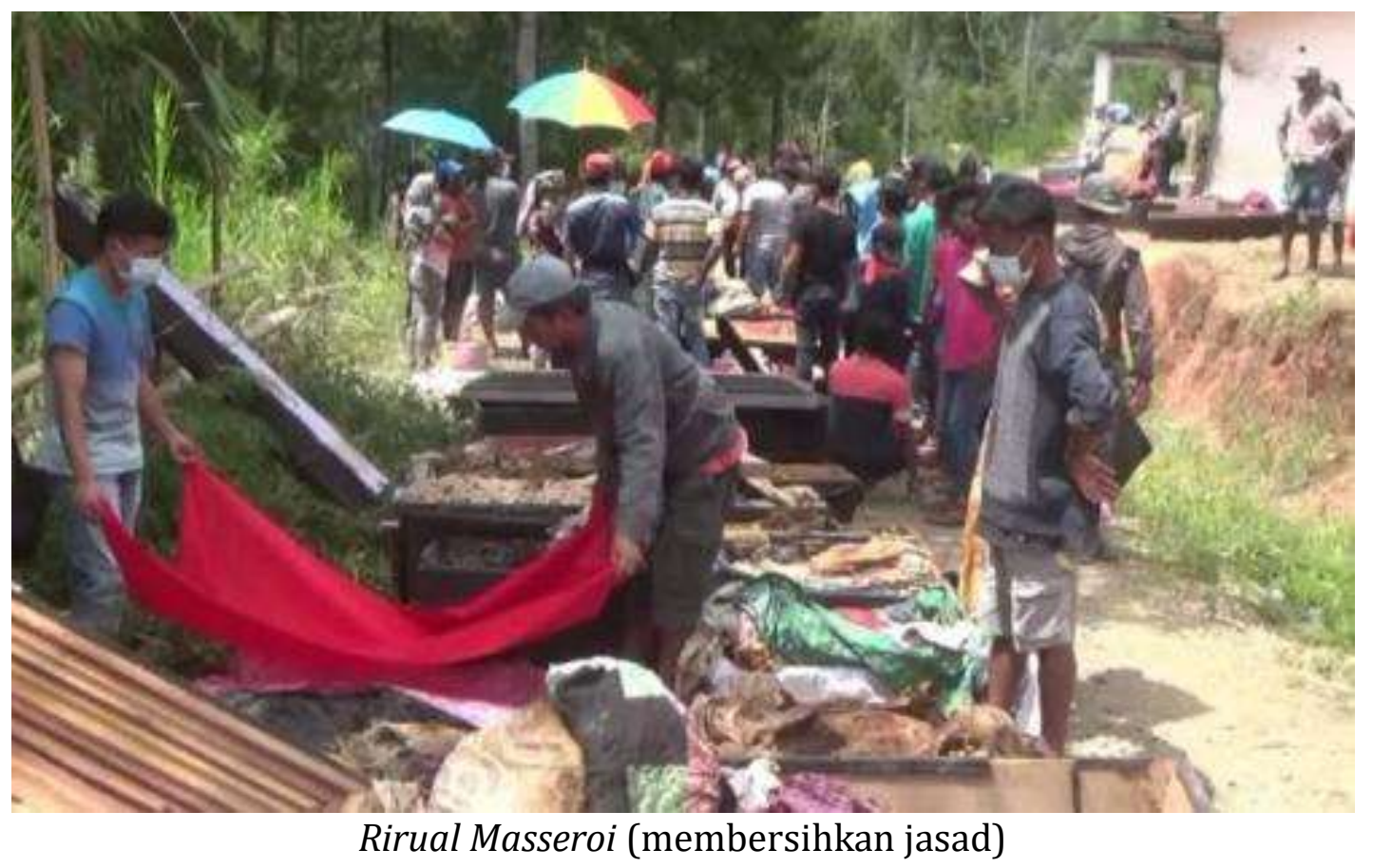




\section{Mangallo Batang Rabuk}

Mangallo batang rabuk berarti menjemur jasad. Mangallo batang rabuk dalam ritual ma'nene' to Sarani merupakan prosesi mengeluarkan mayat dari kuburan dan kemudian dijemur. Prosesi ini dilaksanakan pada hari ketiga. Pada prosesi mangallo batang rabuk, semua mayat dalam liang kubur dikeluarkan lalu dibuka pembungkusnya kemudian dijemur dibawah sinar matahari. Penjemuran jasad ini dilakukan disekitar kuburan. Menjemur jasad ini dilakukan oleh orang-orang yang dianggap sudah tahu dan sudah mengerti tentang cara mangallo ini.

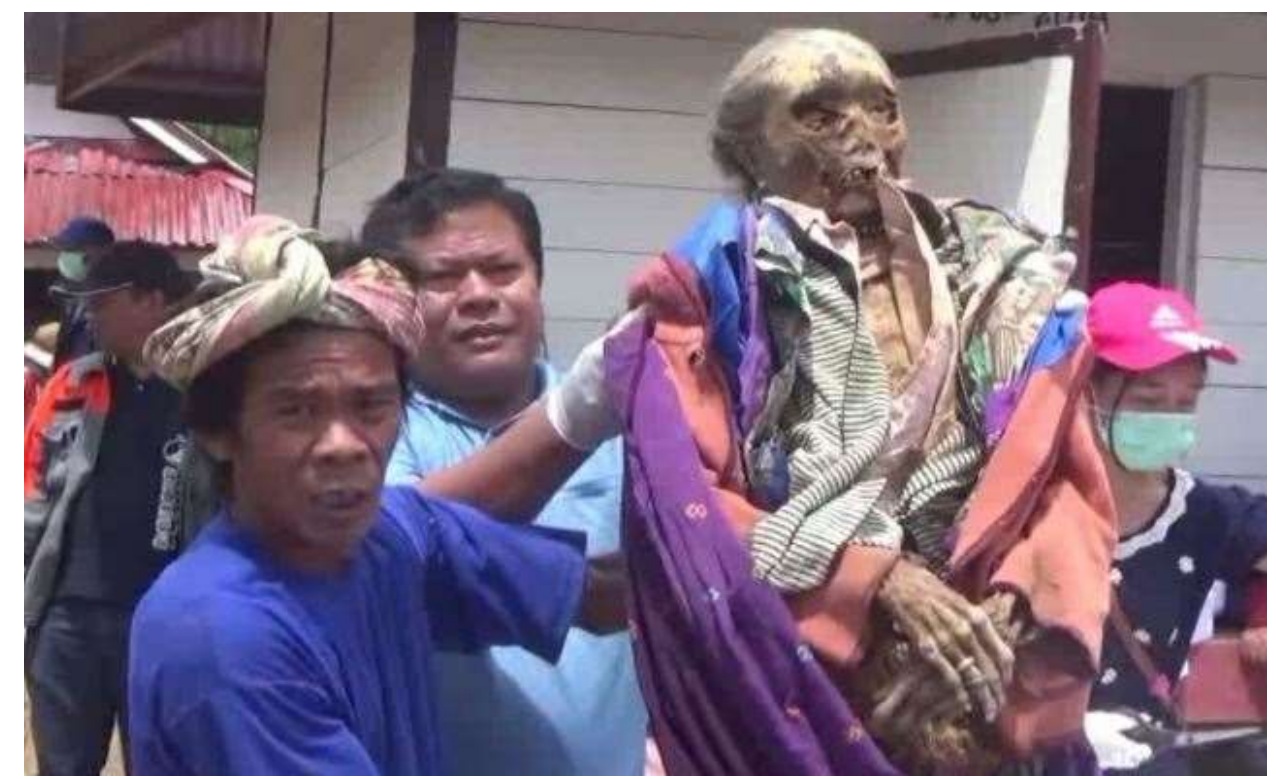

ritual mangallo batang rabuk atau menjemur jasad

\section{Ma'palobo'}

Ma'palobo'berarti menumbuhkan. Ma'palobo' dalam ritual ma'nene' to Sarani adalah prosesi mengganti pembungkus lama dengan pembungkus dari dari jasad . Ma'palobo' ini dilaksanakan pada hari keempat. Akan tetapi, tidak semua jasad diganti pembungkusnya, itu semua tergantung dari keadaan pembungkus jasad, jika sudah rusak maka akan diganti, tetapi jika masih bagus biasanya itu tidak perlu diganti tetapi hanya diperbaiki saja agar tetap bagus. pada prosesi ini, keluarga besar dari mayat-mayat yang hendak diganti pembungkusnya biasanya membawa kain mereka untuk dijadikan pembungkus. Mereka membawa kain ini bukan hanya sekedar untuk membungkus jasad dari keluarga mereka saja, tetapi mereka datang membawa kain untuk dijadikan pembungkus karena mereka meyakini bahwa dengan membawakan kain itu, mereka berarti membagikan sebagian milik mereka kepada yang telah meninggal.

Setelah diganti pembungkusnya, biasanya mayat-mayat ini akan berukuran lebih kecil karena tujuan dari ma'palobo' ini adalah untuk memperkecil ukuran mayat supaya dalam liang kubur tidak terlalu sempit. Pembungkus lama dari mayat-mayat ini biasanya akan dibuang disekitar kuburan itu atau dibuang ke sungai. Pada hari keempat ini, diadakan makan bersama, dan yang menjadi penanggungjawab dari makan bersama ini adalah keluarga yang ingin mengganti pembungkus jasad keluarganya. Makan bersama dilaksanakan setelah mengganti pembungkus jasad sudah selesai. 


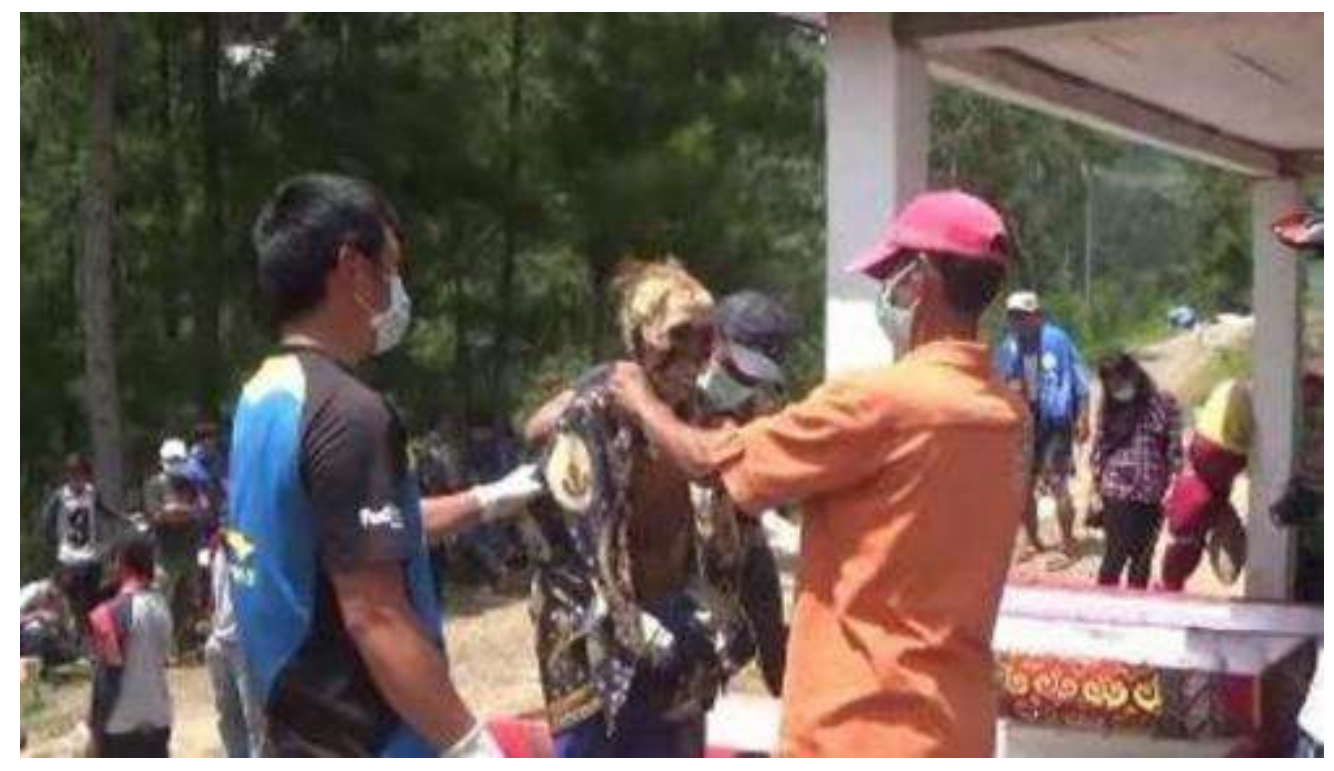

\section{Mangrapa'}

Ritual mangrapa' merupakan rangkaian ritual ma'nene' to sarani yang dilaksanakan pada hari kelima. Mangarapa' merupakan prosesi memasukkan kembali jasad yang sudah dijemur dan diperbaiki pembungkusnya ke dalam liang kubur. Dalam memasukkan jasad ke liang kubur, diperlukan ketelitian yang baik agar tidak salah memasukkan jasad. Ketika memasukkan jasad, yang harus diingat adalah posisi kepala dan kaki, dan juga harus mengingat itu mayat dari keluarga siapa.

\section{Ma'tutu'}

Ritual ma'tutu'yang berarti menutup. Dalam acara ma'nene' yang ditutup adalah liang kubur. Ma'tutu' merupakan rangkaian terakhir dalam ritual ma'nene' to sarani, pada hari terakhir kegiatan yang dilaksanakan, yaitu pertama ibadah bersama yang diadakan di padang alla' atau ditanah kosong sekitaran kuburan. Setelah ibadah dilaksanakan, akan dilaksanakan makan bersama. Pada makan bersama ini semua masyarakat membawa nasi dari rumah mereka masing-masing yang kemudian dikumpul menjadi satu dan kemudian dibagikan kepada orang banyak. Setelah makan bersama, setiap keluarga besar kembali ke kuburan tempat keluarga mereka dan menutup kembali liang kubur tersebut (ma'tutu'). Dengan ditutupnya liang kubur, menandakan bahwa ritual ma'nene' to sarani telah selesai.

\section{Makna Ritual}

Masyarakat Toraja masih kental dengan tradisi Ma'nene. Ritual tersebut dianggap suatu ritual yang unik sehingga perlu dilestarikan karena dengan adanya ritual Ma'nene selain sebagai penghormatan kepada leluhur dan sanak keluarga yang sudah meninggal dunia, hal tersebut merupakan sebagai momen untuk bertemu dengan keluarga yang ada diperantauan untuk dating mengadakan tradisi Ma'nene. Menurut tokoh agama setempat, Pendeta (Pdt) Hilkia Putra Nehemia bahwa "Tradisi budaya warisan nenek moyang diakuinya, tidak bisa begitu saja dipindahkan dari masyarakat lokal, dalam sejarah lokal, Alkitab juga tidak bisa lepas dan dipisahkan dengan Namanya budaya, yaitu budaya Yahudi".

Ritual ini sebagai penghormatan dan bentuk kasih sayang kepada leluhur masyarakat di Kecamatan Denpina dan sekitarnya. Hal tersebut dapat dilihat dengan mengganti pakaian jenazah para pendahulunya. Suku Toraja meyakini bahwa hubungan 468 
keluarga tidak berakhir begitu saja setelah datangnya kematian sehingga Ketika ritual Ma'nen berlangsung, mayat keluarga ataupun kerabat akan dikeluarkan dari tempat penyimpanan, kemudian dimandikan dan dipakaikan pakaian baru dan mewah. Rangkaian proses ritual tersebut wajib diikuti dengan suka cita, tanpa ada perasaan berkabung apalagi sampai menangisi jenazah.

\section{Simpulan}

Berdasarkan hasil penelitian, ditemukan beberapa bentuk prosesi dalam ritual ma'nene', diantara, yaitu: ma'bukka' liang (membuka liang kubur), ma'bawa bunga (membawa berbagai makanan dan minuman ke kuburan), masseroi (membersihkan), mangallo batangrabuk (menjemur jasad), ma'palobo' (mengganti/memperbaiki pembungkus jasad), mangrapa'(memasukkan kembali jasad ke liang kubur), dan ma'tutu'(menutup kembali liang kubur).

\section{Ucapan Terima Kasih}

\section{Daftar Pustaka}

Alfadilah, Andari Novianti. (2020). “Mengenal Ma'nene', Ritual Mengganti Pakaian Mayat di Toraja, Sulawesi Selatan". https://kumparan.com/kumparantravel/mengenal-manene-ritual-menggantipakaian-mayat-di-toraja-sulawesi-selatan-1tBLo7QWmt8

Chaer, Abdul. (1995). Pengantar Semantik Bahasa Indonesia.J Jakarta: Rineka Cipta.

Hoed, Benny H. (2008). Semiotik dan dinamika Sosial Budaya. Depok: Komunitas Bambu. Indarwati, I., Mariana, L., \& Rachman, S. (2018). "Ritual Para Bissu, Para Waria Sakti di Kabupaten Bone". Jurnal Idiomatik.

Indarwati, Nur Fadny Yuliani, \& Lina Mariana. (2020). "Ritual Mattompang Arajang, Prosesi Penyucian Benda Pusaka Kerajaan Bone: Tinjauan Semiotik Budaya". Jurnal Onoma: Pendidikan, Bahasa, Dan Sastra. https://doi.org/10.30605/onoma.v6i2.388

Koentjaraningrat. (2004). Kebudayaan Mentalis dan Pembangunan. Jakarta: PT Gramedia Pustaka Utama.

Mattulada (1985). "Latoa: Satu Lukisan Analitis Terhadap Antropologi-Politik". Makassar: LEPHAS.

Sobur, Alex. 2006. Semiotika Komunikasi. Bandung: PT Remaja Rosdakarya.

Sugiyono. (2017). Metode Penelitian Kuantitatif, Kualitatif, dan R\&D. Bandung: Alfabeta.

Teeuw, A. (1984). Khasanah Sastra Indonesia. Jakarta: Balai Pustaka

Veronica, Celine. (2019). "Ma'nene' Ritual Mayat Ratusan Tahun Barganti Pakaian". https://nationalgeographic.grid.id/read/131834324/manene-toraja-ritualmayat-ratusan-tahun-berganti-pakaian.'tutu'(menutup kembali liang kubur). 